$\xi_{\mathrm{P}}=1$

\title{
Dynamic Characterization of Single Lap Joints in Composite Laminate over Experimental and Computational Approach
}

\author{
J.V.Muruga Lal Jeyan ${ }^{1}$, Akhila Rupesh ${ }^{2}$, Jency Lal ${ }^{3}$ \\ ${ }^{I}$ Professor, Lovely professional university \\ ${ }^{2} \mathrm{PhD}$ Scholar, Lovely professional university \\ ${ }^{3}$ Students affairs head Satyam College of Engineering and Technology
}

\begin{abstract}
The purpose of the project investigates the mechanical characterization of single lap joints namely bonded, riveted \& hybrid joints an experimentally and numerically. One of the primary entanglements in the investigation of the mechanics of the composite material is the multiphase disappointment conduct. In the meantime, it is hard to describe all the disappointment modes from a solitary situated example. The outcome of the present venture uncovers the way that the mechanical attributes of the half breed single lap joint is enhanced when contrasted and the qualities of adhesively fortified single lap joints in composite cover. The structure comprises of a get together of substructures appropriately masterminded and associated with frame a heap transmission way. Such load transmission way is accomplished utilizing joints. Joints constitute the weakest zones in the structure. Along these lines, to use the maximum capacity of composite materials, the quality and stress conveyance in the joints must be seen so reasonable arrangement can be decided for different applications, for example, aviation, car and marine enterprises.
\end{abstract}

Keywords: Experimental Investigation, Fatigue Failure, composites Failure, Hybrid joint, composite lap joints.

\section{Introduction}

Any number papers can easily be found for mechanically fastened joints and adhesive bonded joints whereas for hybrid joints, there are only a limited number of papers available. Some of them are briefly discussed below.

1. Hart-Smith directed a hypothetical examination of consolidated fortified/catapulted ventured lap joints amongst titanium and Carbon Fiber Reinforced Plastic (CFRP). While no huge quality advantages were found in contrast with superbly fortified joints, the consolidated shot reinforced joint was observed to be helpful for repairing harmed reinforced joints and restricting harm engendering. Under room temperature and encompassing moistness conditions, $98 \%$ of the connected load was anticipated to be exchanged by the adhesive[2]. Chan and Vedhagiri examined the utilization of blasted, reinforced and consolidated fortified catapulted joints utilized as a part of repair. A solitary tie joint with CFRP adherends was considered with two jolts utilized as a part of the cover district. The investigation fundamentally considered pressure circulations in the overlays and constrained thought was given to stack exchange through the joint. The auxiliary reaction of different setups of single lap joint, specifically, reinforced, shot and fortified darted joints, was broke down by three-dimensional limited component strategy. For the instance of half and half joints, it was discovered that the jolts don't play a functioning part in stack exchange before the commencement of the disappointment. Nonetheless, the jolts in the half and half joint really diminish the in-plane hub worry close to the edge of overlap.[3].

A trial and numerical investigation on the impacts of decrease edges and cover length on the disappointment and stress conveyance of adhesively fortified single lap joints-This paper analyzes the disappointments and qualities of joints reinforced by a Neoxil CE92 N8 glue at various cover lengths and diverse decrease edges. The examination was completed both as trial and numerical. In the test arrange, lap-shear tests on Single-Lap Joints (SLJs) with various decrease points and cover lengths were directed. The pressure examinations in the SLJs were acquired utilizing a straight Finite Element Analysis (FEA) in numerical stage. It is expected that glue and adherend have both geometrical nonlinearity and straight material conduct. Investigating deliberately the surfaces of the SLJs, two diverse disappointment writes, durable disappointments (CF) and exceptional durable disappointments (SCF) were watched. The got numerical outcomes were contrasted and trial ones. Results show that the expanding of both cover length and decrease edge increment the joint quality and, specifically, the most astounding quality qualities in every joint geometry are achieved by examples having a decrease edge of $15^{\circ}$. [4]. The composite basic individuals are exceptionally utilized as a part of the accompanying applications, for example, aviation, autos, automated arms, engineering and so forth., has pulled in broad consideration in the previous decades. In such applications and furthermore to join different composite parts together, they are affixed together either utilizing glues or mechanical latches. The motivation behind the venture is to explore the mechanical quality of the twofold tie joints in the composite 
overlay. In this present work, GFRP composite Lap joints with various stacking groupings, for example, $0 \mathrm{o}$, point handle $[+45 \mathrm{o} /-$ $45 \mathrm{o}$, cross utilize [0o/90o] are utilized to decide the mechanical quality and diverse disappointment instruments when subjected to elastic test. The heap versus relocation esteems will be resolved utilizing Universal Testing Machine (UTM). The exploratory outcomes will be contrasted and them. From the exploratory perception, greatest extreme burdens and most extreme removals are found for composite lap joints with zero degree introduction contrasted and $[0 \mathrm{o} / 90 \mathrm{o}]$ and $[45 \mathrm{o} / 45 \mathrm{o}]$ composite twofold tie joints. In view of the exploratory outcomes, Composite tie joints with zero degree introduction are appropriate introduction for basic applications.4. Static and Fatigue Testing of Thick Adhesive Joints for Wind Turbine Blades - Experimental outcomes are exhibited for the static and weakness qualities of thick cement joint examples which are illustrative of sharp edge joints. Four firmly related geometries are investigated, with more than 250 individual tests; exhaustion stacking conditions incorporate both strain and turned around stacking. The four geometries are contrasted likewise with static quality measurements and exhaustion lifetime patterns. Break roots and split development modes are portrayed for each case, alongside run of the mill imperfections identified with the lower quality examples. Limited component examination is utilized to investigate associations between joint geometry, nearby pressure focuses and pore areas. [5]The wedge write three cone shaped tests or yaw meter is arranged by their stun wave edge and made-up agreeing the pre-determined measurements. The inscribed wedge compose test (yaw meter) setup is made to successful examination and productively tested by methods for the CFD 2D and 3D examination strategies. With the outcome, the mach esteem tends to improve, with the stun wave point getting decreased. At the supersonic level, the arranged test puts within proper limits the weight and temperature of the wind current at mach 2.8 and to the tune of mach 3 levels. The inscribed wedge write test is abused in the even movement and the yaw pivot point minutes are assessed. It is planned with the assistance of the stain less steel material for its firmness. The days are not far-removed when these composite materials are consolidated like the mixing of titanium and pottery for strengthening the material in raised temperature esteems and better hardness metals and furthermore than plan the yaw meter setup either in vertical hub premise or in both pivot minute reason for procuring rich reaps in execution of the yaw meter. [6].Failure modes on Fiber Reinforced Plastics (FRP) under exhaustion stacking and watched utilizing Scanning Electron Microscope. The weakness conduct was found in three areas and in these districts, the grid break inception, fiber disappointment and fiber-lattice delamination, exhaustion development amid stacking process were found. Under cyclic stacking, the harm will amass in composite materials. This reason the break/split or practical disappointment of structures. For isotropic materials with indistinguishable every which way material properties, harms heaped up at a low development rate at the outset, and a single crack spreads an opposite way to the cyclic stacking pivot. The expanding number of cycles causes fiber disappointment. The framework and fiber harms brings about debilitating of the composite example. Filtering electron magnifying instrument strategy hows, the harm is constituted by the crack of the fiber and grid and recognize their development system under weariness loadings, checking electron magnifying lens perceptions are in concurrence with these outcomes as got from the experimental test.[7]. Adhesively fortified joints in composite materials A audit of the examinations that have been made on adhesively fortified joints of fibre-strengthened plastic (FRP) composite structures (single skin and sandwich development) is introduced. The impacts of surface arrangement, joint configuration, glue properties, and natural factors on the joint conduct are depicted briefly for adhesively fortified FRP composite structures. The explanatory and numerical strategies for stretch examination required before disappointment expectation are talked about. The numerical methodologies cover both straight and non-direct models. A few techniques that have been utilized to anticipate disappointment in reinforced joints are depicted. There is no broad assention about the strategy that ought to be utilized to anticipate disappointment since the disappointment quality and modes are distinctive as per the different holding techniques and parameters, yet dynamic harm models are very encouraging since essential parts of the joint conduct can be demonstrated by utilizing this approach. Nonetheless, an absence of dependable disappointment criteria still exists, restricting along these lines a more far reaching use of adhesively fortified joints in main loadbearing basic applications. A precise quality expectation of the adhesively fortified joints is fundamental to diminish the measure of costly testing at the plan arrange.

\section{Manufacturing Process of Laminate}

Vaccum Bagging: shaping uses an adaptable film to encase the part and seal it from outside air. A vacuum is then drawn on the vacuum pack and climatic weight packs the part amid the fix procedure. Vacuum sack material is accessible in tube or a sheet material. At the point when a tube formed tube is utilized then the whole part can be encased inside the pack. When utilizing the sheet sacking materials, the edge of the vacuum pack are fixed against the edges shape surface to encase the part against a water/air proof form. At the point when sacked along these lines, the lower shape is unbending structure and the upper surface of the part is framed by the adaptable layer vacuum bag. The adaptable film can be reusable silicone material or an expelled polymer film. In the wake of fixing the part inside the vacuum sack, a vacuum is drawn on the part amid fix. This procedure can be performed at either surrounding or lifted temperature with encompassing barometrical weight following up on the vacuum pack. A vacuum pump is normally used to draw a vacuum. A conservative technique for drawing is with a wander vacuum and air compressor. A vacuum pack is sack made of solid elastic covered texture or a polymer used to pack the part amid a fix or a solidifying procedure. In some application the sack encases the whole material or in different applications a shape is utilized to frame the one face of the cover with the pack being a solitary layer to seal the external edge of the form confront. When utilizing a tube formed pack the finish of the sack are fixed and the air is drawn out of the pack through areola utilizing a vacuum pump. Accordingly uniform weight moving toward one air is connected to the surface of the question inside the sack, holding parts together while glue fixes. The whole sack might be put in temperature controlled broiler, oil shower or water shower and delicately warmed to quicken relieving.

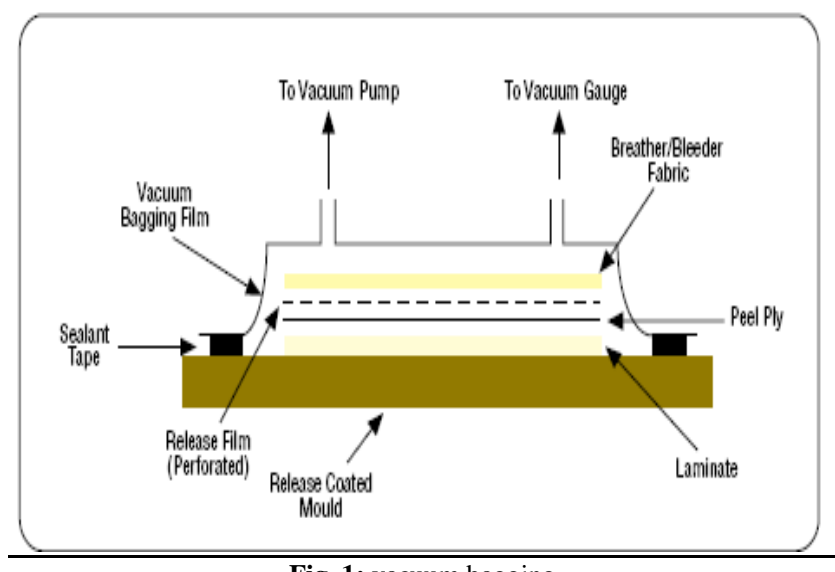

Fig. 1: vacuum bagging 
Release Film (Teflon) It is used to separate the component from the breather. Release film is made by Teflon, FEE fluorocarbon materials; perforated release film is used to extract the volatile gases formed during the curing process.

Peel Ply: A closely woven nylon or polyester cloth is used as the layer of the composite during layup. The tearing or peeling process fracture the resin matrix coating and exposed a clean virgin roughened surface for the bonding process.

Cold Spray: A cold spray is used to remove the protective film from the prepregs Cleaning agents and protective Barrier cream is applied to hands during lay up of prepregs. Soap solution is used to clean the hands after layup.

Release All: A liquid material used on the tools and other surface where Demoulding is required.

Breather: The breather cloth is used to provide path to extract the entrapped air and volatile contents.

Bagging Film: Bagging film is a flexible membrane, which covers the component, breather, release film etc. the bagging film is scaled all round the edges of the component to allow the desired vacuum and pressure for curing of the component. The bagging film is made of high temperature nylon material.

Sealant: It is used to seal the bagging material on the tool surface. The sealant is made by high temperature modified silicon, which is extruded out in a bead film. The self-life of the sealant is six months.

Curing: is to irreversibly change the properties of a thermosetting resin by chemical reaction, .e. condensation, ring closure or addition. Cure cycle is the time, temperature and pressure cycles used to cure a thermosetting resin or a pre-peg. Curing time varies from 30 minutes To 180 minutes.

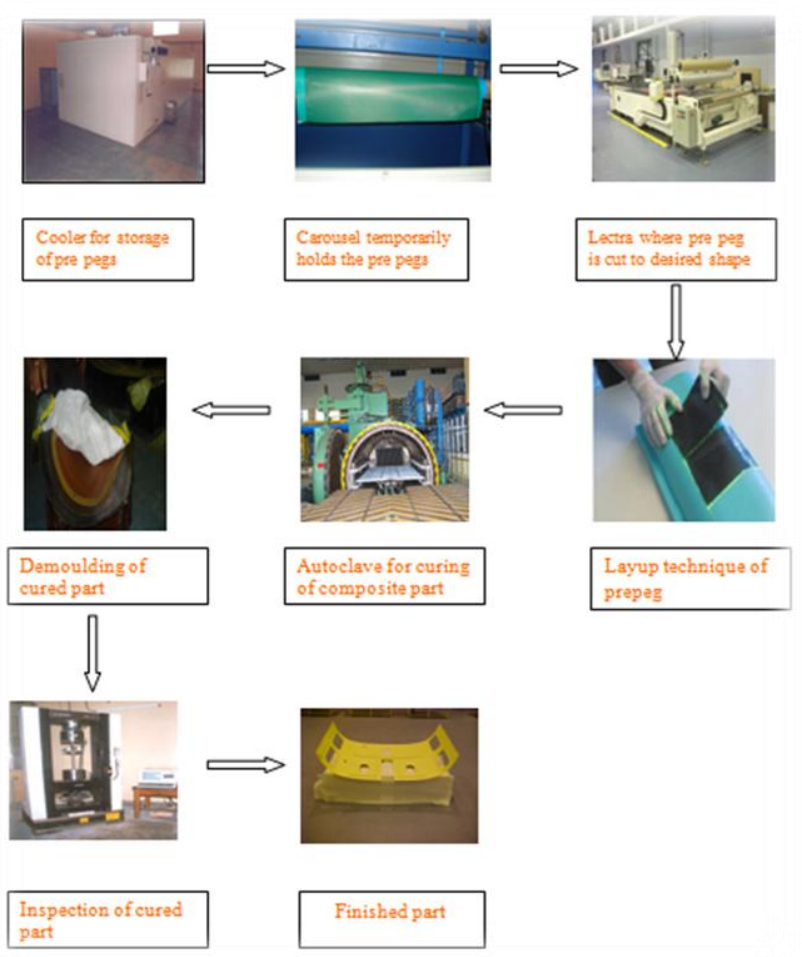

Fig. 2: Manufacturing cycle of composites

\section{Software and Hardware Requirement}

Reinforced joints can be made by sticking together pre-relieved covers with the reasonable glues or by shaping joints amid the assembling procedure, in which case the joint and the overlay are restored in the meantime (co-relieved). Here, stack exchange between the substrates occur through a dissemination of shear worries in the adhesive. In general, there are various focal points of glue reinforced joints over the conventional mechanical secured joints. These favorable circumstances incorporate huge security zone for stack exchange, low pressure focus, smooth outer surfaces at the joint, less affectability to cyclic stacking, time and cost sparing, high quality to weight proportion, electrical and warm protection, conductivity, erosion and weakness opposition, split hindrance, damping attributes.

\section{Specimen Preparation for Bonded Joint}

A layer of gum is connected with a brush on the gel coat which has just gelled or restored. The cut glass fiber tangle is put over the tar. By a stripling activity utilizing tar wetted brush; the gum is crushed to the best surface utilizing discharging film. Care will be taken to see that the expected glass-to-sap proportion is consistently acquired. Utilizing vacuum process, the layer is solidified and the air bubbles expelled. It is vital that all the air captured in the primary layer is evacuated. Something else, the air ensnared between gel coat and first layer of tangle will extend later causing rankling. Nearby bits of mats will be legitimately covered. After the principal layer is laid up, ensuing layers are laid up in a comparative way appeared in the figure 3 and 4 .

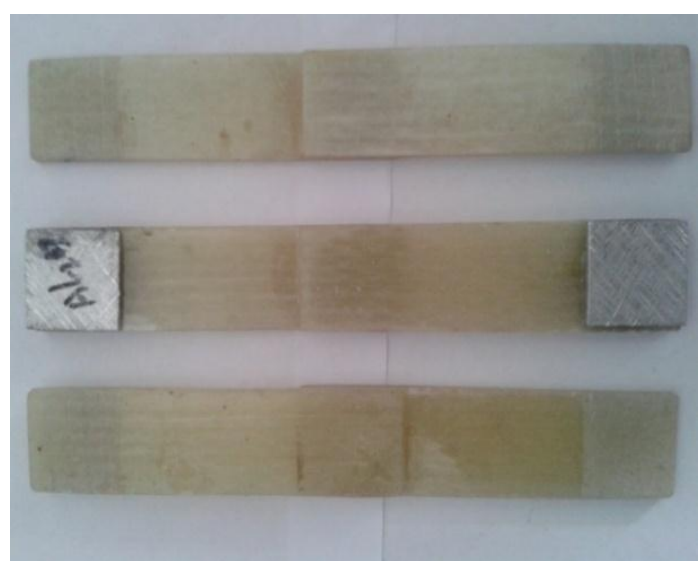

Fig. 3: Single lap Bonded Joints -ASTM standard

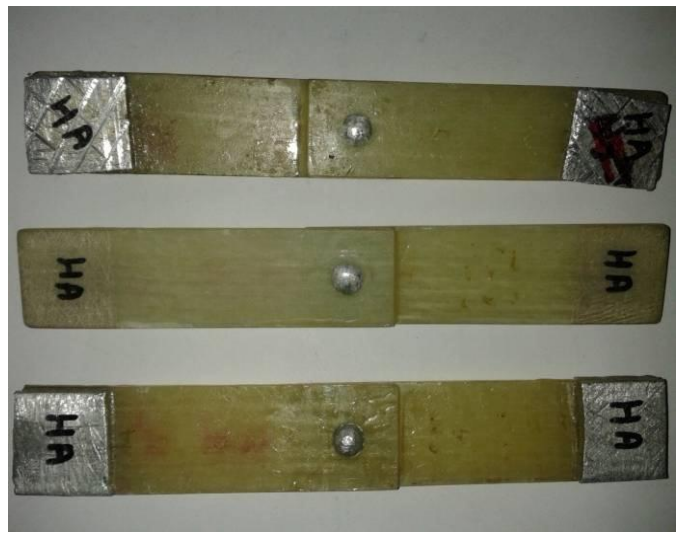

Fig. 4: Single lap hybrid (bonded-riveted) Joints -ASTM standard 


\section{Mechanical Characterization of Single Lap Joint}

Ductile test is directed to decide the elastic properties of the material especially composites appeared in the figure 12. ASTM (American measures for testing of Materials) ASTMD638-03.This particular gives the attracting of the example to be set up for directing the test with resiliences. The arranged pliable example were examined subsequent to machining and stacked in the tractable testing machine or all inclusive testing machine and the ductile power is given pressure Vs strain bend is created till the example is broken.

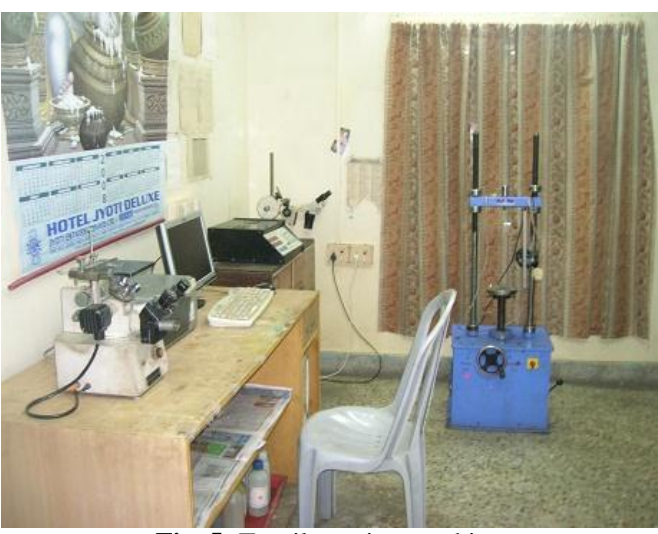

Fig. 5: Tensile testing machine

\section{Bonded Joint Result after Testing}

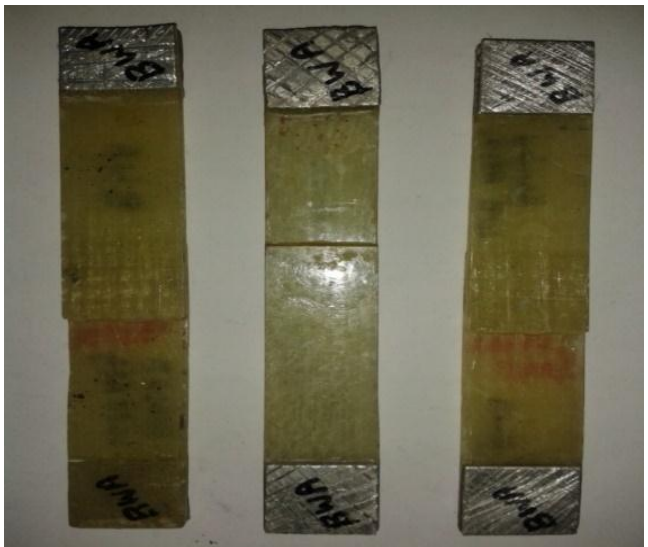

a)

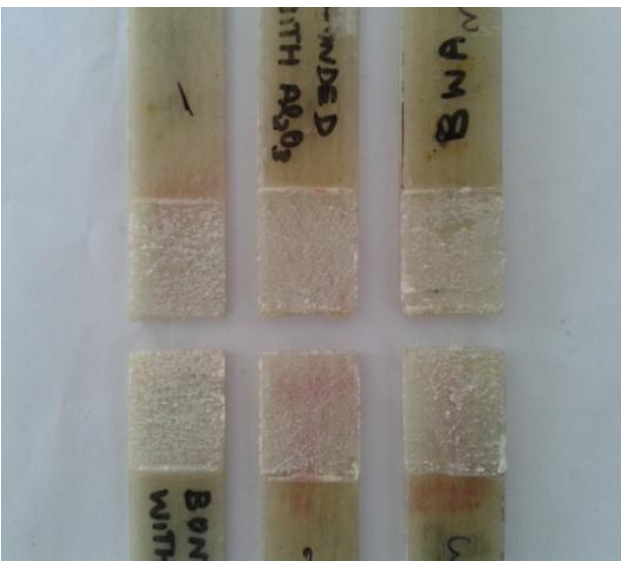

b)

Fig. 6: Adhesively bonded lap joint specimens (a) before testing and (b) after testing

\section{Specimen 1}

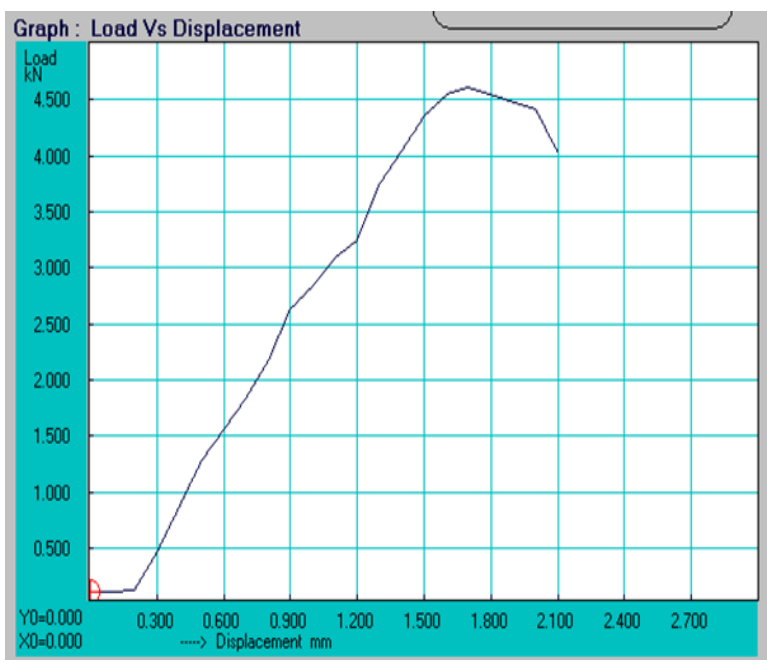

\begin{tabular}{|l|c|}
\hline Ult./Break Load & $4.605 \mathrm{kN}$ \\
\hline Disp. at FM.AX & $1.700 \mathrm{~mm}$ \\
\hline Max. Disp. & $2.100 \mathrm{~mm}$ \\
\hline A.rea & $208.000 \mathrm{~mm}^{2}$ \\
\hline Ult. Stress & $0.022 \mathrm{kN} / \mathrm{mm}^{2}$ \\
\hline Elongation & $5.250 \%$ \\
\hline Yield Stress & $0.021 \mathrm{kN} / \mathrm{mm}^{2}$ \\
\hline YS/UTS Ratio & 0.958 \\
\hline
\end{tabular}

Fig. 7: Load vs Displacement curve of adhesively bonded joint

\section{Specimen 2}

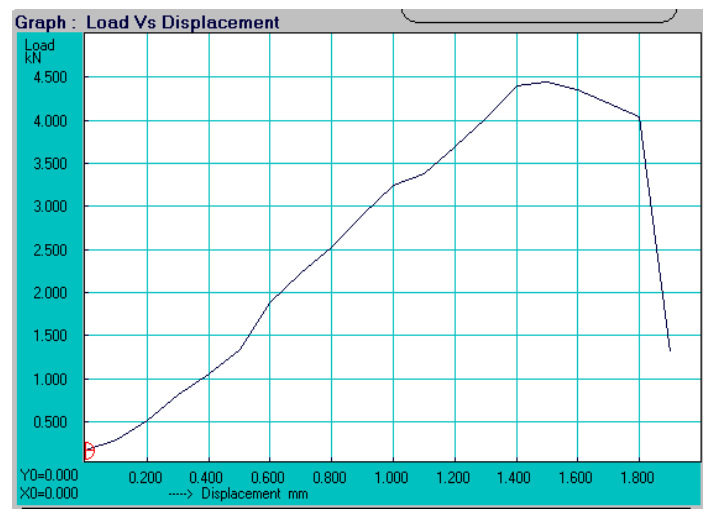

\begin{tabular}{|l|c|}
\hline \multicolumn{1}{|c|}{ Ult./Break Load } & $4.445 \mathrm{kN}$ \\
\hline Disp. at FM.AX & $1.500 \mathrm{~mm}$ \\
\hline Max. Disp. & $1.900 \mathrm{~mm}$ \\
\hline Area & $208.000 \mathrm{~mm}^{2}$ \\
\hline Ult. Stress & $0.021 \mathrm{kN} / \mathrm{mm}^{2}$ \\
\hline Elongation & $4.750 \%$ \\
\hline
\end{tabular}

Fig. 8: Load vs Displacement curve of adhesively bonded joint 


\section{Specimen 3}

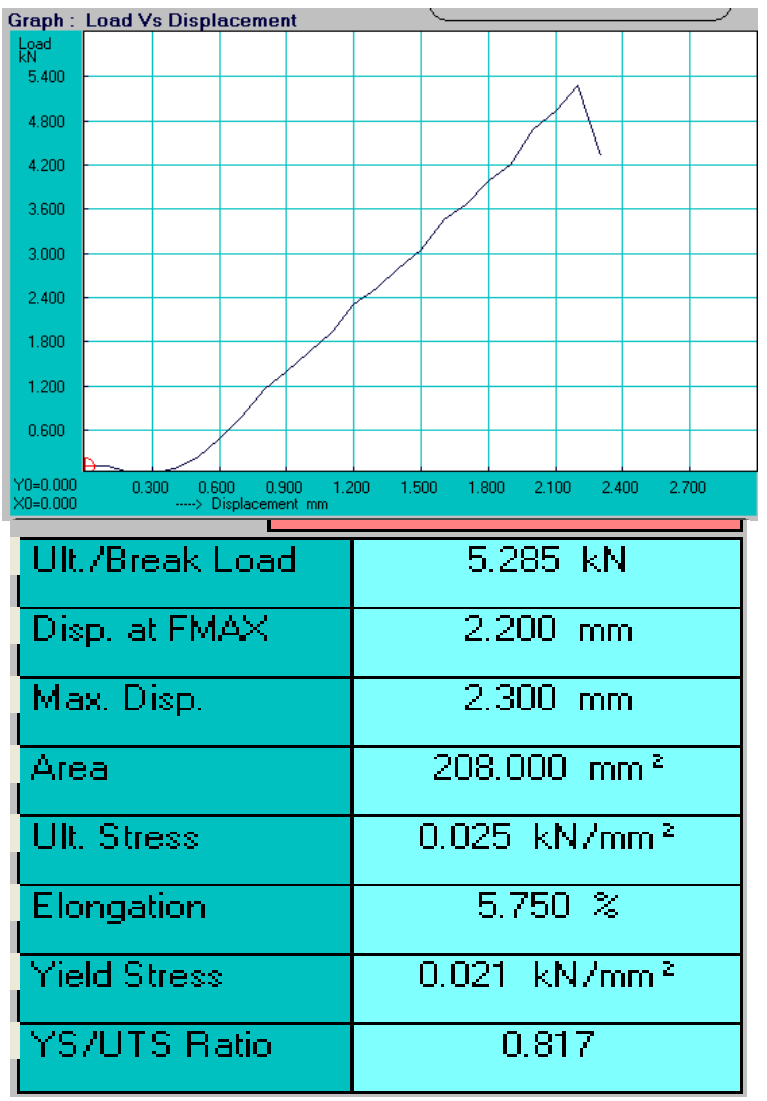

Fig. 9: Load vs Displacement curve of adhesively bonded joint

\section{Specimen 4}

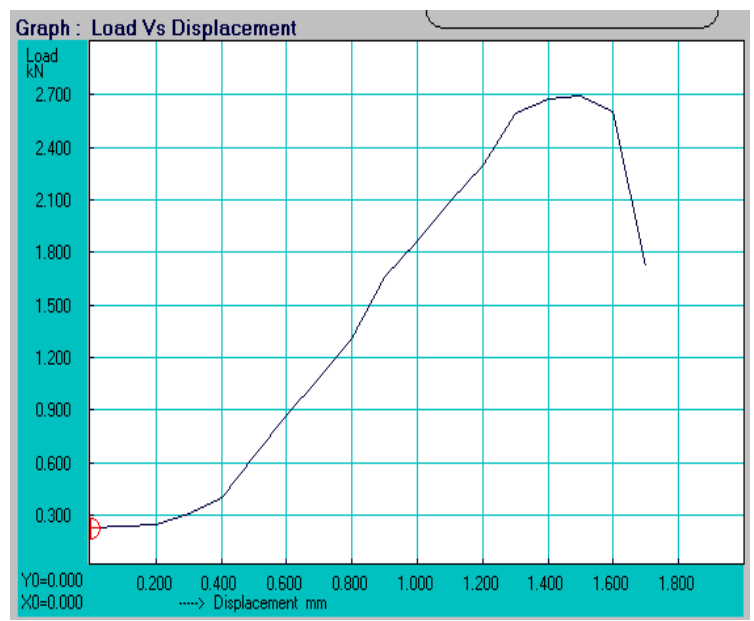

\begin{tabular}{|l|c|}
\hline \multicolumn{1}{|c|}{ Ult./Break Load } & $2.690 \mathrm{kN}$ \\
\hline Disp. at FM.AX & $1.500 \mathrm{~mm}$ \\
\hline Max. Disp. & $1.700 \mathrm{~mm}$ \\
\hline Area & $208.000 \mathrm{~mm}^{2}$ \\
\hline Ult. Stress & $0.013 \mathrm{kN} / \mathrm{mm}^{2}$ \\
\hline Elongation & $4.250 \%$ \\
\hline Yield Stress & $0.013 \mathrm{kN} / \mathrm{mm}^{2}$ \\
\hline YS/UTS Ratio & 0.967 \\
\hline
\end{tabular}

Fig. 10: Load vs Displacement curve of adhesively bonded joint

From the figure 14, 15, 16 and 17, when the machine starts applying tensile load, specimen tends to stretch with respect to applying load. The crosshead speed of $1.5 \mathrm{~mm} / \mathrm{min}$ is maintained. The load acts at the area where the adhesive bonding is made. The applied load gradually weakens the chemical bonding between the adhesive and the substrate, causing the adhesively bonded single lap joint to fail. Consequently the specimen gets broken at a particular time under the influence of the applied load and the value is noted as ultimate break load. Since the failure occurs between the adhesive and the substrate and also exclusively within the FRP adherend, near the surface, characterized by a thin layer of the FRP resin matrix visible on the adhesive, with few or no glass fibers transferred from the adherend to the adhesive, it is clear that the adhesive failure and the light-fibre tear failure occurs at the specimen during testing. The software starts generating graph for load vs displacement. Since load is directly proportional to the displacement, the curve gradually increases in the graph until the specimen fails. The load at which the specimen gets failed is known as ultimate break load. The curve starts to descend gradually when the ultimate break load is attained. After the specimen is failed, graph is obtained. The same procedure is done for three more specimens and the average load and displacement value is determined.

\section{Hybrid Joint}

When the machine starts applying tensile load, specimen tends to stretch with respect to applying load. The crosshead speed of $1.5 \mathrm{~mm} / \mathrm{min}$ is maintained. The load acts at the area where the adhesive bonding and the rivet is placed. The applied load gradually weakens the chemical bonding between the adhesive and the substrate and also the rivet between the substrates. Consequently the specimen gets broken at a particular time under the influence of the applied load and the value is noted as ultimate break load. Since hybrid joint is the combination of adhesive bonded and riveted joint, failures such as adhesive, light-fibre tear failure and shear failure occurs while the specimen is subjected for testing.

The software starts generating graph for load vs displacement. Since load is directly proportional to the displacement, the curve gradually increases in the graph until the rivet fails and then the curve drops and then ascends until the adhesive bond fails. After that the curve starts descending. Hence the curve experiences a fluctuation in hybrid single lap joint indicating the failures occurring at the rivet and adhesive bond consecutively. The load at which the specimen gets failed is known as ultimate break load. After the specimen is failed, graph is obtained. The same procedure is done for three more 
specimens and the average load and displacement value is determined as shown in the figure 19, 20, 21 and 22.

\section{Hybrid Joint Result after Testing}

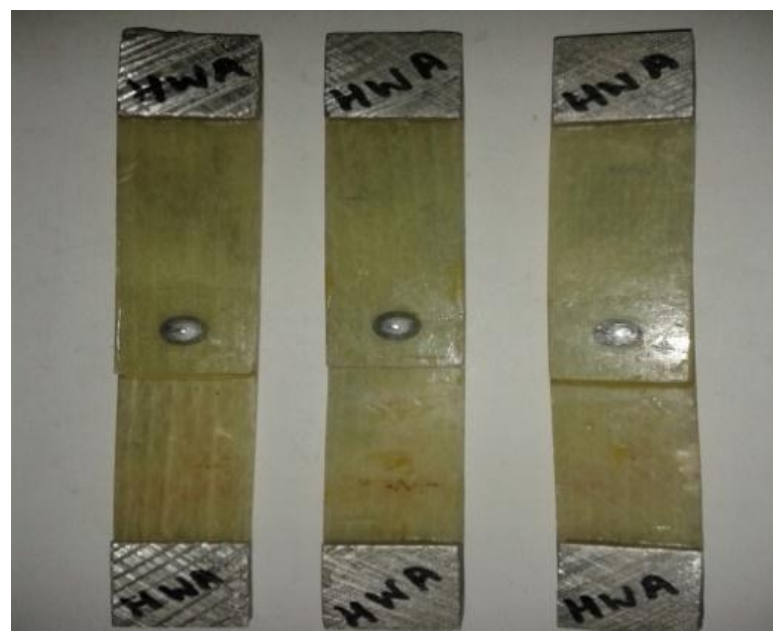

a)

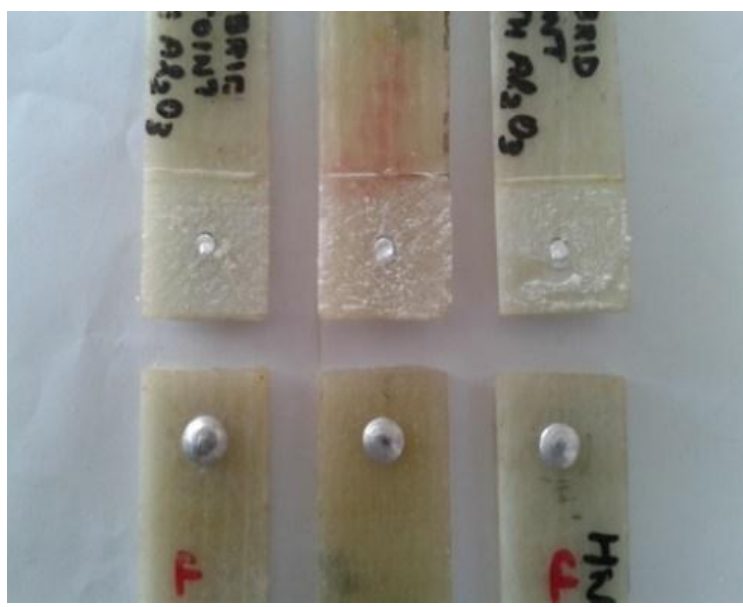

b)

Fig. 11: Hybrid single lap joint specimens (a) before testing and (b) after testing

\section{Specimen 1}

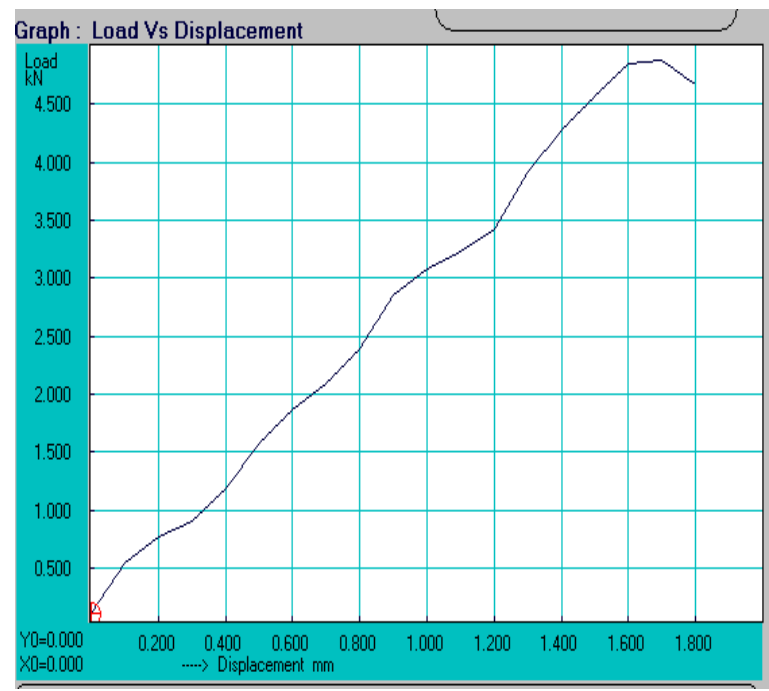

\begin{tabular}{|l|c|}
\hline Ult./Break Load & $4.880 \mathrm{kN}$ \\
\hline Disp. at FMAX & $1.700 \mathrm{~mm}$ \\
\hline Max. Disp. & $1.800 \mathrm{~mm}$ \\
\hline Area & $202.500 \mathrm{~mm}^{2}$ \\
\hline Ult. Stress & $0.024 \mathrm{kN} / \mathrm{mm}^{2}$ \\
\hline Elongation & $6.923 \%$ \\
\hline Yield Stress & $0.006 \mathrm{kN} / \mathrm{mm}^{2}$ \\
\hline YS/UTS Ratio & 0.242 \\
\hline
\end{tabular}

Figure 12: Load vs Displacement curve of hybrid single lap joint

\section{Specimen 2}

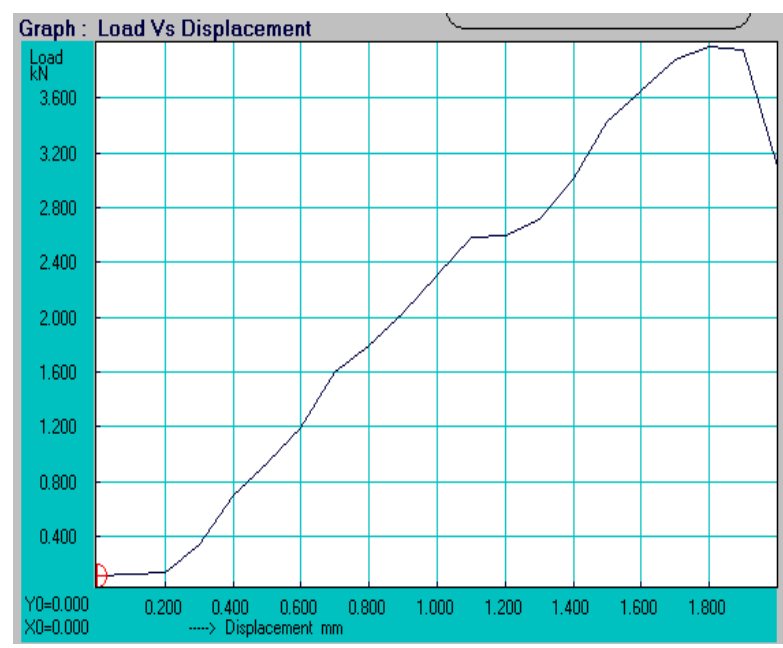

\begin{tabular}{|l|c|}
\hline \multicolumn{1}{|c|}{ Ult./Break Load } & $3.975 \mathrm{kN}$ \\
\hline Disp. at FMAX & $1.800 \mathrm{~mm}$ \\
\hline Max. Disp. & $2.000 \mathrm{~mm}$ \\
\hline Area & $208.000 \mathrm{~mm}^{2}$ \\
\hline Ult. Stress & $0.019 \mathrm{kN} / \mathrm{mm}^{2}$ \\
\hline Elongation & $5.000 \%$ \\
\hline Yield Stress & $0.015 \mathrm{kN} / \mathrm{mm}^{2}$ \\
\hline YS/UTS Ratio & 0.780 \\
\hline
\end{tabular}

Fig. 13: Load vs Displacement curve of riveted single lap joint 


\section{Specimen 3}

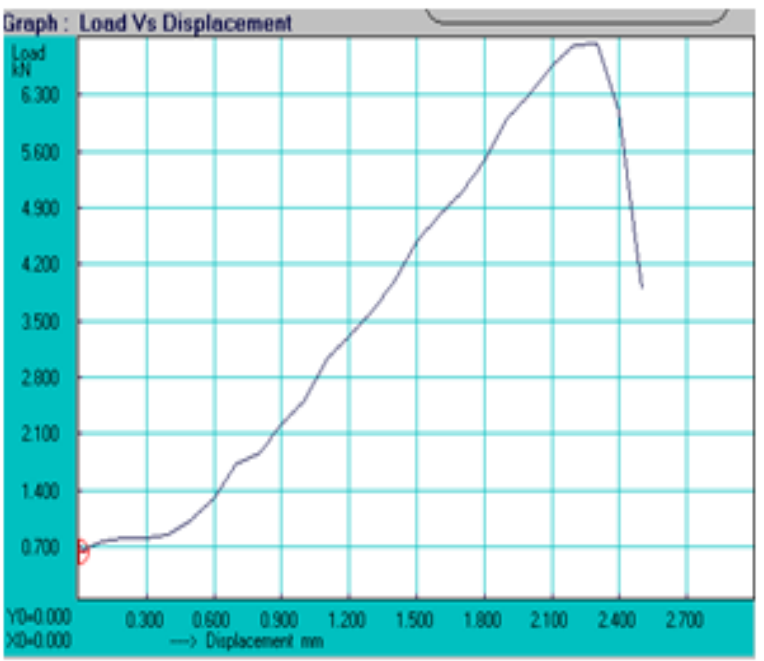

\begin{tabular}{|l|c|}
\hline Ult./Break Load & $6.930 \mathrm{kN}$ \\
\hline Disp. at FMAX & $2.300 \mathrm{~mm}$ \\
\hline Max. Disp. & $2.500 \mathrm{~mm}$ \\
\hline Area & $208.000 \mathrm{~mm}^{2}$ \\
\hline Ult. Stress & $0.033 \mathrm{kN} / \mathrm{mm}^{2}$ \\
\hline Elongation & $6.250 \%$ \\
\hline Yield Stress & $0.029 \mathrm{kN} / \mathrm{mm}^{2}$ \\
\hline YS/UTS Ratio & 0.880 \\
\hline
\end{tabular}

Fig. 14: Load vs Displacement curve of hybrid single lap joint

\section{Specimen 4}

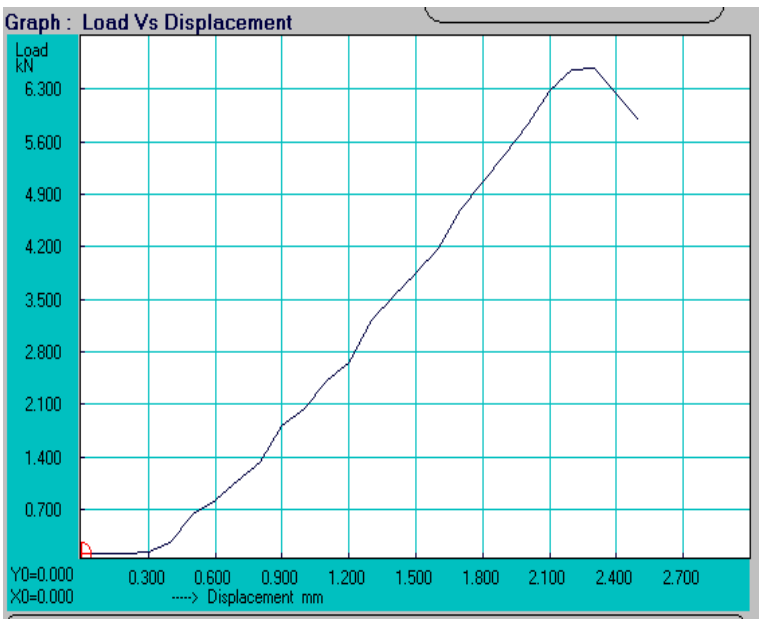

\begin{tabular}{|l|c|}
\hline Ult./Break Load & $6.590 \mathrm{kN}$ \\
\hline Disp. at FMAX & $2.300 \mathrm{~mm}$ \\
\hline Max. Disp. & $2.500 \mathrm{~mm}$ \\
\hline Area & $208.000 \mathrm{~mm}^{2}$ \\
\hline Ult. Stress & $0.032 \mathrm{kN} / \mathrm{mm}^{2}$ \\
\hline Elongation & $6.250 \%$ \\
\hline Yield Stress & $0.028 \mathrm{kN} / \mathrm{mm}^{2}$ \\
\hline YS/UTS Ratio & 0.892 \\
\hline
\end{tabular}

Fig. 15: Load vs Displacement curve of hybrid single lap joint

\section{Modules Description}

The hybrid joint's strength is higher than adhesive bonded and riveted joint strength. The hybrid joints characterize higher reliability during long-term working. The purpose of the project investigates the mechanical characterization of single lap joints namely bonded, riveted \& hybrid joints an experimentally and numerically. One of the main complications in the study of the mechanics of the composite material is the multiphase failure behavior. From ANSYS results, failure was occurred on the overlap region at edge of the lap joints and maximum stresses were located in the failure region. Experimental results are validated with ANSYS results.

\section{Results and Discussion}

\section{Single Lap Joint Bonded Joints}

The adhesively bonded joint specimens were tested and the values were determined and tabulated. The average ultimate load and displacement of bonded joint were found to be $4.78 \mathrm{KN}$ and 1.76 $\mathrm{mm}$ shown in the figure 23 . The ultimate failure load and elongation of each specimen was tabulated at below table 1 . After the tests were completed, the specimen displacements and the failure loads were recorded and the average values were determined and tabulated.

Table 1: Ultimate Load and Displacement for bonded lap joint

\begin{tabular}{|c|c|c|c|c|c|c|c|}
\hline \multicolumn{2}{|c|}{$\begin{array}{c}\text { Ult./Break load } \\
\text { (KN) }\end{array}$} & \multicolumn{3}{|c|}{$\begin{array}{c}\text { Displacement } \\
(\mathbf{m m})\end{array}$} & $\begin{array}{c}\text { Average } \\
\text { Load } \\
(\mathbf{K N})\end{array}$ & $\begin{array}{c}\text { Average } \\
\text { Displacement } \\
(\mathbf{m m})\end{array}$ \\
\hline Sp1 & Sp2 & Sp3 & Sp1 & Sp2 & Sp3 & \multirow{2}{*}{4.78} & 1.76 \\
\hline 4.61 & 4.45 & 5.29 & 1.7 & 1.5 & 2.2 & & 1.76 \\
\hline
\end{tabular}

\section{Load vs Displacement}

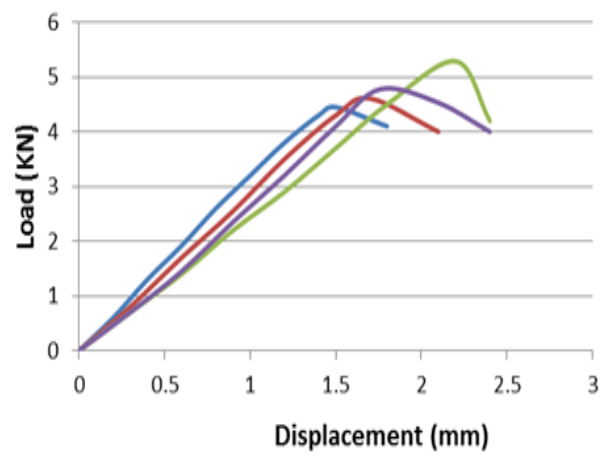

Fig. 16: Load Vs Displacement curve of bonded joint 


\section{Hybrid Joint}

The normal extreme load and removal of half breed joint with were observed to be $5.59 \mathrm{KN}$ and $2.03 \mathrm{~mm}$ as appeared in the figure 24 . A definitive disappointment load and prolongation of every example was arranged at underneath table 1 . After the tests were finished, the example relocations and the disappointment loads were recorded. Plainly the normal extreme heap of half and half joint is more prominent than cross breed joint $(4.99 \mathrm{KN})$. This obviously shows the mechanical qualities of the half breed joint are superior to the crossover joint.

Table 2: Ultimate Load and Displacement for hybrid lap joint

\begin{tabular}{|c|c|c|c|c|c|c|c|c|c|}
\hline \multicolumn{4}{|c|}{$\begin{array}{c}\text { Ult./Break load } \\
(\mathrm{KN})\end{array}$} & \multicolumn{4}{|c|}{$\begin{array}{c}\text { Displacement } \\
\text { (mm) }\end{array}$} & \multirow{2}{*}{$\begin{array}{c}\text { Avg } \\
\text { Loa } \\
\text { d } \\
\text { (KN } \\
\quad) \\
\end{array}$} & \multirow{2}{*}{$\begin{array}{c}\text { Avg } \\
\text { Displaceme } \\
\text { nt } \\
(\mathbf{m m})\end{array}$} \\
\hline Sp1 & Sp2 & $\begin{array}{c}\mathrm{Sp} \\
3\end{array}$ & $\begin{array}{c}\text { Sp } \\
4\end{array}$ & $\begin{array}{c}\text { Sp } \\
1\end{array}$ & $\begin{array}{c}\text { Sp } \\
2\end{array}$ & $\begin{array}{c}\text { Sp } \\
3\end{array}$ & $\begin{array}{c}\text { Sp } \\
4\end{array}$ & & \\
\hline $\begin{array}{c}4.8 \\
8\end{array}$ & $\begin{array}{c}3.9 \\
8\end{array}$ & 6.9 & 1.7 & 1.7 & 1.8 & 2.3 & 2.3 & 5.59 & 2.03 \\
\hline
\end{tabular}

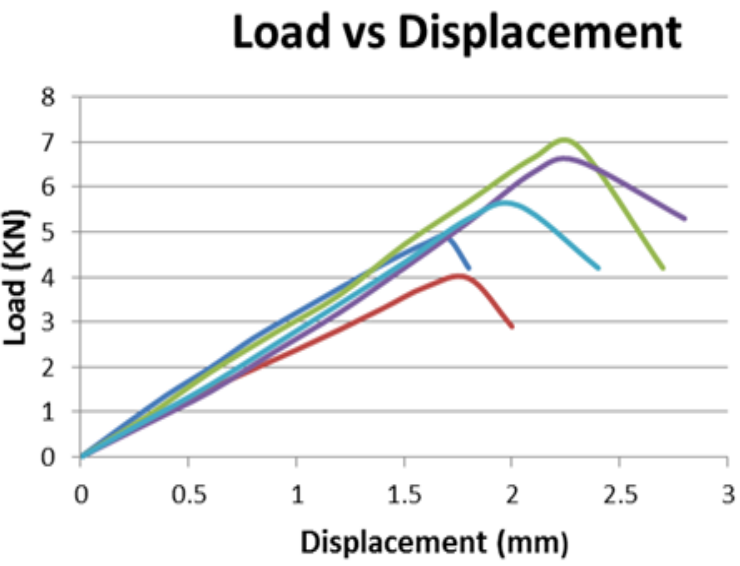

Fig. 17: Load Vs Displacement curve of hybrid joint

\section{Finite Element Analysis of Single Lap Joints}

The picked limited component code has been the business bundle ANSYS because of its adaptability for taking care of data contained in records written in a pretty much free organization. In the static examination the cutting edge diversion and the von Misses stresses were analysed. Failure stack forecast is acquired utilizing ANSYS FEA apparatus. The business FEA programming ANSYS 10 has been utilized to dissect the models. The overlays (disciple) were made of Glass/epoxy composite with 00 degree introduction and the glue utilized was standard Epoxy based gum. The composite covers of FEA show for fortified joints were created by utilizing Layered 46, a 3-D block component. The cement layer was demonstrated utilizing SOLID-45, a 8-hub block component. The disciple and cement were stuck together utilizing Boolean task. Better work was utilized as a part of the plan. The fortified joints with lattice conditions are appeared in the figure 18 .

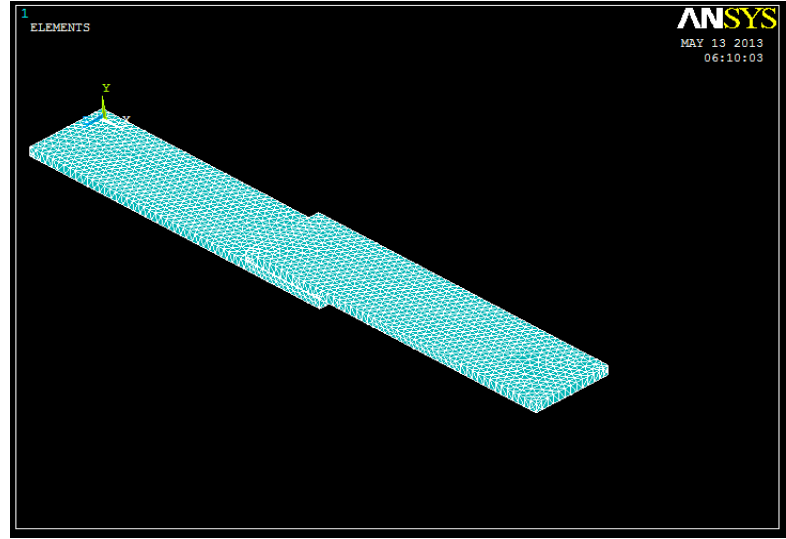

Fig. 18: Meshed model of single lap bonded joints

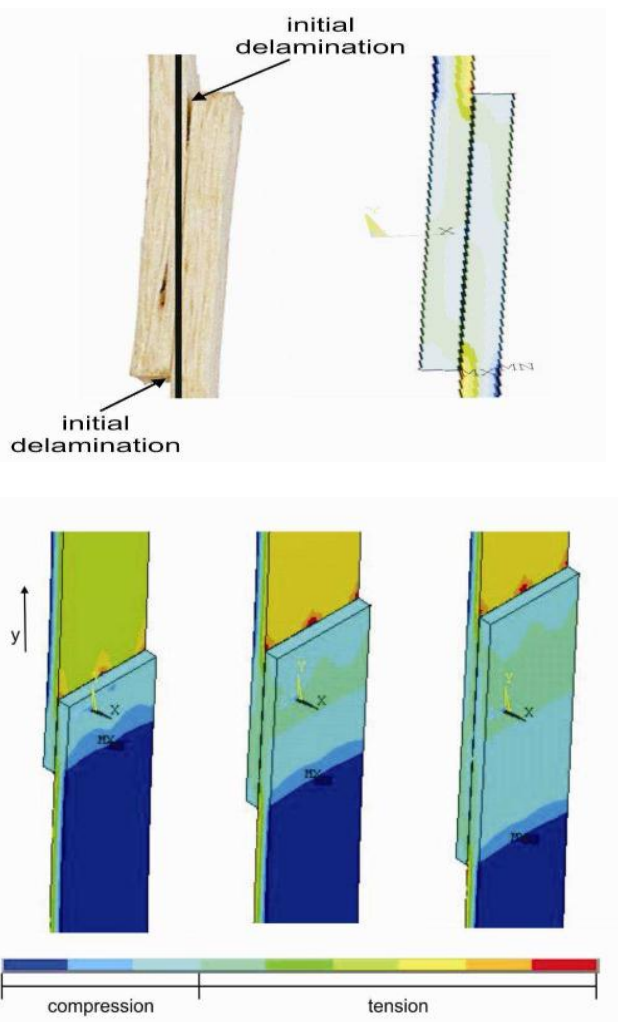

Fig. 19: Failure observed on overlap region in bonded lap joints

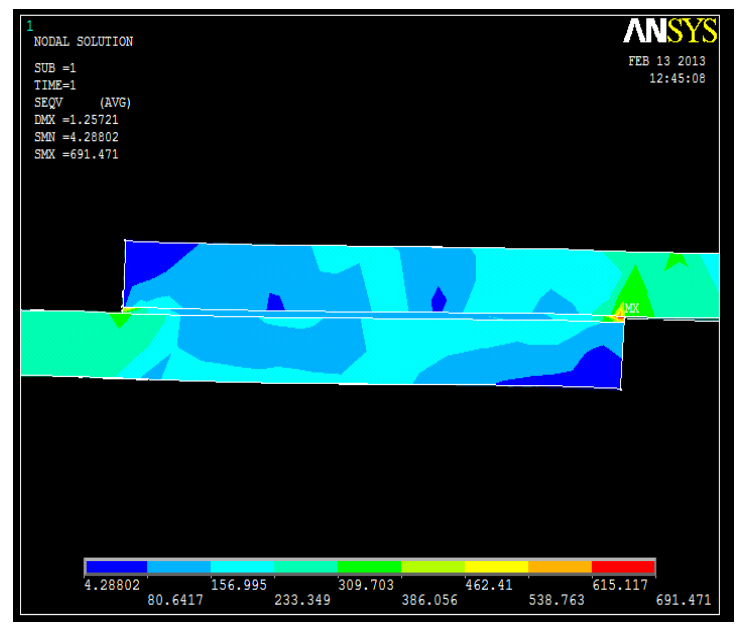

Fig. 20: FEA results of bonded lap joints 
In adhesive joints, the applied loads on the adherends are transferred on to the adhesive layer mainly by stresses. In bonded joints, the stress was distributed throughout the laminate and the adhesive took up much of the load shown in figure 19 and 20.

\section{Conclusion}

The hybrid (adhesive bonded and riveted) joints have widely used in different branches of engineering application such as aerospace, mechanical, civil, etc.

The hybrid joint's strength is higher than adhesive bonded and riveted joint's strength. The hybrid joints characterize higher reliability during long-term working. The purpose of the project investigates the mechanical characterization of single lap joints namely bonded, riveted \& hybrid joints an experimentally and numerically. One of the main complications in the study of the mechanics of the composite material is the multiphase failure behavior. At the same time, it is difficult to characterize all the failure modes from a single oriented specimen. The consequence of the current project reveals the fact that the mechanical characteristics of the hybrid single lap joint is improved when compared with the characteristics of adhesively bonded single lap joints in composite laminate. Thus from the present study, it was found that a welldesigned hybrid joint is very efficient when compared to bonded or riveted joints. Hence hybrid joints are highly preferable in case of repair situations in aircraft structures. From ANSYS results, failure was occurred on the overlap region at edge of the lap joints and maximum stresses were located in the failure region. Experimental results are validated with ANSYS results

\section{Future Enhancement}

The hybrid (adhesive bonded and riveted) joints have widely used in different branches of engineering application such as aerospace, mechanical, civil, etc. The consequence of the current project reveals the fact that the mechanical characteristics of the hybrid single lap joint is improved when compared with the characteristics of adhesively bonded single lap joints in composite laminate. Thus from the present study, it was found that a well-designed hybrid joint is very efficient when compared to bonded or riveted joints. Hence hybrid joints are highly preferable in case of repair situations in aircraft structures.

\section{Output Screenshots}

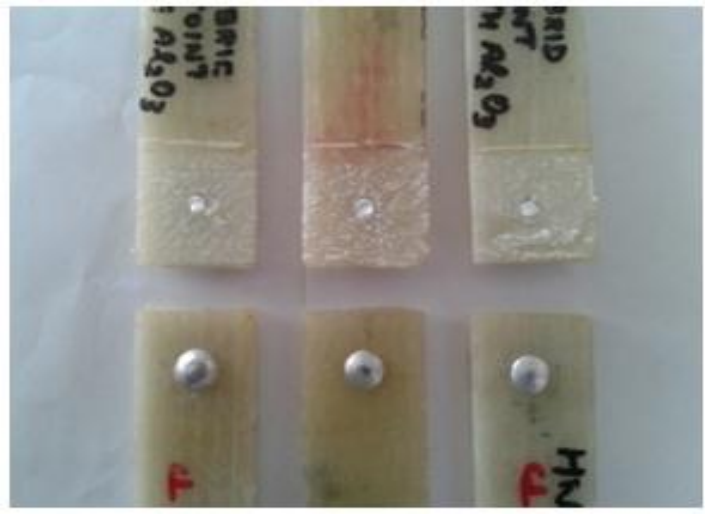

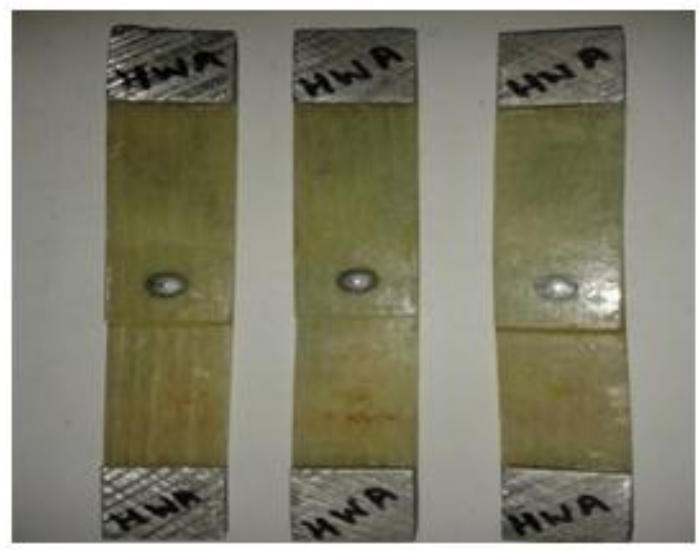

\section{References}

[1] Cole, W.F., "Technical Justification of Repairs to Composite Laminates," International on Aircraft Damage and Repair, Melbourne, Australia, 1991.

[2] Hart-Smith, L.J., "Adhesive Bonded Scarf and Stepped Lap-Joints," NASA-CR-112237, January 1973.

[3] Byron Pipes, R. and Adkins, W., "Strength and Mechanics of Bonded Scarf Joints forRepair of composite Materials," NASA-CR-169708 Final Report, May 1982.

[4] J V Muruga Lal Jeyan. and Akhila Rupesh, "Experimental analysis of composite laminate on double lap joints with different orientation" ,International Journal of Advance Research In Science And Engineering IJARSE, Vol. No.4, Issue 01, PP 323-335, January 2015 , ISSN-2319-8354.

[5] J V Murugalal Jeyan, Dr. M. Senthil Kumar, "Performance Evaluation of Yaw Meter With the Aid of Computational Fluid Dynamic" , International Review of Mechanical Engineering (IREME). ISSN: 1970-8734, Vol No. 8, Issue 02

[6] Naisha Muhammed, J. V. Muruga Lal Jeyan "Fatigue Failure Fiber Reinforced Plastics Under Cyclic Reversed Loading Modes" Transactions on Innovations in Science and Technology Vol.No.02, Issue 01 December 2016 PP: 80-84, E-ISSN: 2456-5075

[7] Reinhart, J.T., Engineered Materials Handbook, Volume 3, Adhesives and Sealants,ASM International Handbook Committee, December 1990

[8] Hoyt. D. M, Pierre J. Minguet and Stephen H. Ward .., "Strength and Fatigue Life Modeling of Bonded Joints in Composite Structure"2003.

[9] F. Fassio. S. Santini. T. Vallee "Tensile Tests On Bonded DoubleStrap Joints Between Pultruded GFRP Profiles" Department of structural engineering. University degli studi "roma tre". ITA Composite construction laboratory. Swiss federal instate of technology. I ausanne, Switzerland.

[10] H.K. Lee, S.H. Pyo, B.R. Kim “On Joint Strengths, Peel Stresses And Failure

[11] Modes In Adhesively Bonded Double-Strap And Supported SingleLap GFRP Joints"

[12] ASTM D5573-99 "standard Practice for Classifying Failure Modes in Fiber- Reinforced- plastic(FRP) Joints" American Society for Testing and Materials, West Conshohocken, PA, United states. 